\title{
Preparing the Leaders for Mechatronics Education
}

\author{
Sema E. Alptekin \\ Industrial and Manufacturing Engineering Department \\ Cal Poly, San Luis Obispo \\ salpteki@calpoly.edu
}

\begin{abstract}
Mechatronics is the synergetic combination of precision mechanical engineering, electronic control and systems thinking in the design of products and processes. There is a need to develop interdisciplinary programs in Mechatronics that better prepare our graduates to design, build, and operate the products and systems of today and tomorrow. To address this need, National Science Foundation funded a project entitled "Preparing the Leaders for Mechatronics Education" undertaken by Cal Poly in 1995 - 1996. In this paper, the activities that took place during this two-year program is outlined. Several courses and course modules have already been developed and implemented by the participants of this program for their own universities. Some of their pioneering work in this field is also summarized.
\end{abstract}

\section{Introduction}

Mechatronics is a synthesis of "Mechanical electronics", two distinct technological areas that overlap in the design of complex systems. A recent definition of Mechatronics which is also accepted by the European Community is as follows: Mechatronics is the synergetic combination of precision mechanical engineering, electronic control and systems thinking in the design of products and processes [1].

Most advanced products today are complex systems, composed of integrated mechanical and electronic components that operate with the aid of control and decision making software. Intelligent washing machines eliminate sorting, microwaves come with programs to make popcorn and auto-defrosting. Products employing microcomputers are called "Smart Products" [2]. Design, fabrication and operation of such smart products require an intimate knowledge of various engineering disciplines.

The need for better communication between the design and manufacturing engineers gave birth to concurrent (or simultaneous) engineering. If the product or system that is being designed has only mechanical components, then concurrent engineering would provide an environment for design engineers to make sure that what they design would be manufacturable. If the product is a "smart product" -- with mechanical, electronic, and software components, then the concurrent engineering definition should be expanded to allow full integration of other disciplines. A proposed model to illustrate mechatronics technologies, smart product, and concurrent engineering relationships is shown in Figure $1[3]$.

The " $x$ " axis in this model represents the size of the product ranging from consumer products to agile manufacturing systems. The "y" axis is the technologies represented in the product or system being designed: Electronics, mechanical, and software. Synergistic integration of these technologies in the design of smart products and intelligent systems, as explained above, is referred to as "Mechatronics". The " $\mathrm{z}$ " axis shows the phases of the development process: design, manufacturing, and operation. Through this visual display, we see the different phases of development in three dimensional space.

As mechatronics evolves, new technologies will be added to the " $y$ " axis in the future. Bio-Mechatronics, for instance, is being explored by Japanese researchers to utilize biological components in the design of smart products. Use of an insect antennae removed from a male silk moth in steering a mobile robot to follow the pheromone trace from a female insect is a good example of Bio-Mechatronics [4].

There is a need to develop interdisciplinary programs in Mechatronics that better prepare our graduates to design, build, and operate the products and systems of today and tomorrow. To address this need, National Science Foundation funded a project entitled "Preparing the Leaders for Mechatronics Education" undertaken by Cal Pol in 1995 - 1996. The strong response to the initial announcement of our program in 1995 confirmed the existence of a high degree of interest and need in this area among the engineering academic community. A summary of the activities that took place during this two-year program is provided in the next section. Several courses and course modules have already been developed and implemented by the participants of this program at various universities. Some of their pioneering work in this field is outlined in the last section of this paper. 


\section{NSF Sponsored Mechatronics Workshop}

In 1994, NSF's Division of Undergraduate Education supported our proposal to prepare undergraduate faculty members to launch and lead interdisciplinary courses in "Mechatronics" at their institutions. Detailed information about this program is documented at: http://www.calpoly.edu/ salpteki/

This project consisted of the following three phases: - a six-day workshop at Cal Poly (Summer 1995) involving hands-on projects to design and manufacture a

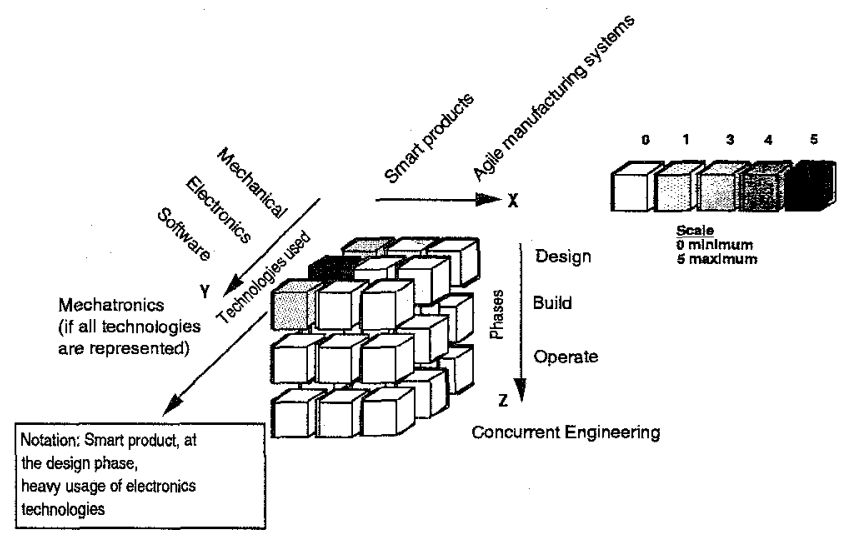

Figure 1: A Suggested Model for Mechatronics

smart product,

- a one year follow-through phase (1995-1996) during which the participants implemented Mechatronics course modules at their home institutions, and

- a two-day follow-up session (Summer 1996) in which the participants reported on their efforts to introduce new concepts at their institutions.

The first phase of the project was offered June 19-24, 1995. Forty-one faculty members from thirty-seven universities nationwide attended the workshop. The following Engineering disciplines were represented: Aerospace, Computer, Electrical, Industrial, Mechanical and Manufacturing Engineering, Computer Science and Engineering Management. The focus of this workshop was to provide faculty members the teaching tools that can be used to train tomorrow's engineers in this evolving "Mechatronics" field. The following topics were covered in the workshop by an interdisciplinary team of instructors from Cal Poly, Stanford University and UC Berkeley:

- Technologies: Microprocessors, Stepper Motors, Servo Motors, and Sensors

- Design: Integrated design and manufacturing, Software Design Methodologies
- Manufacturing: Circuit board design, phototool development and board manufacturing, Metal removal and Sheet Metal Fabrication

- Control Software: C Programming and Fuzzy logic

These topics were briefly introduced in the morning sessions followed by extensive hands-on laboratory sessions. A special attempt was made to integrate the topics covered in the workshop through the use of a common project. A video camera tracking system was developed for this purpose by a group of students and instructors at the Industrial and Manufacturing Department (IME) of Cal Poly, San Luis Obispo. The tracker sits between a video camera and its tripod and rotates the video camera toward a light source that is held by the user. This simple product demonstrates how "building blocks of Mechatronics" such as microprocessors, sensors, stepper motor, intelligent software, and various mechanical components work together. Details of this product are documented in several publications [5-7]. During the lab sessions of the workshop, the participants worked on the design and development of the mechanical, electronic, and software components of this product. The Mini Board, designed by Fred Martin of MIT [8], was introduced to the participants to be used as the control unit of the tracker. The tracker has since been used at various universities to introduce Mechatronics concepts at the undergraduate and graduate levels $[9,10]$.

By the end of the the workshop, the participants were equipped with the teaching tools that they needed to initiate Mechatronics modules and courses. A dialogue was established among the participants before the workshop, in order to assist them in developing a small laboratory at their home institutions to facilitate rapid implementation of new ideas after their return. The same network was also utilized during the follow-through phase to exchange ideas and to provide technical support by the instructional team as needed. This laboratory and the network were key elements in allowing the participants to rapidly implement the new ideas presented at the workshop during the follow-through phase (1995-1996) of the program.

The follow-up conference -- Mechatronics' 96 was conducted on June 13-15, 1996 in San Francisco. The Mechatronics' 96 proceedings documents results of the participants' efforts in the development of Mechatronics curricula [11]. Several participants have already developed courses and many others are performing pioneering work in this field as reported in the proceedings of the follow-up conference. An overview of select implementation efforts along with our efforts in the development of Mechatronics course modules at Cal Poly is presented in the following section. 


\section{Mechatronics Courses}

Development of several undergraduate and graduate level specialized courses in Mechatronics have been reported [11], [12]. The main objective of these courses is to familiarize the students with the capabilities of microprocessors and electronics.

At Cal Poly, one junior undergraduate level course -IME 356 Manufacturing Automation -- was modified to include Mechatronics lectures, laboratory assignments, and term projects. This course is offered twice a year as an elective course for Industrial and Manufacturing Engineering and Mechanical Engineering students. It provides an overview of the building blocks of automation -- sensors, stepper motors, actuators, robots, vision systems, programmable logic controllers, and communication networks. A seven-station laboratory affords students the opportunity to work with industrialgrade equipment and to apply theoretical concepts introduced during formal lecture sessions [13].

A Mechatronics Design Studio has been developed along with the course modules in Mechatronics [14]. The students are provided with building blocks of mechatronics -- sensors, physical modeling kits, a MiniBoard, a C programming environment, a C compiler, and a limited budget. Once the design is verified, the students then utilize the equipment in the manufacturing engineering facilities of IME Department to fabricate a prototype of the smart product.

The ultimate goal in this class is the synergistic fusion of these "Building Blocks" into a Mechatronics strategy to design, build, and control smart products. The students are asked to design and build a prototype smart product as their term project. Use of similar projects to motivate student learning have been reported in literature [12]. One common project in Mechatronics area is to design and build a car (Figure 2) that would perform certain tasks.

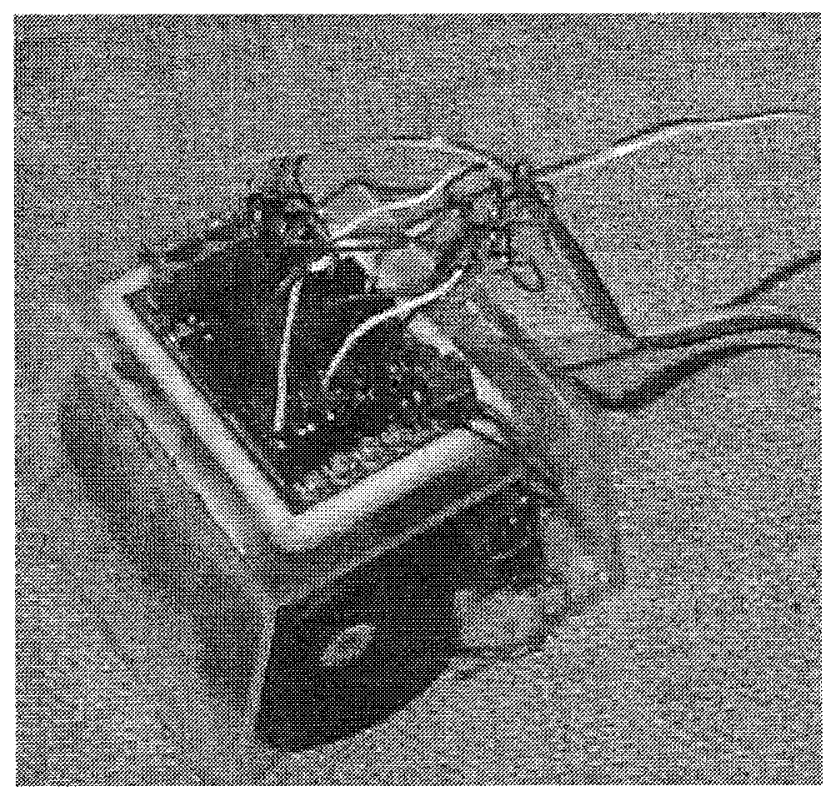

Figure 2: The Goal

The project shown in Figure 2 -- the "Goal" was designed and built by three Mechanical Engineering students as a term project for IME 356 [15]. The "Goal" consists of a $11.5 \mathrm{~cm} \mathrm{x} 11.5 \mathrm{~cm} \mathrm{x7} \mathrm{cm}$ plexiglass chassis that houses: two 3.6 degree stepper motors, a Mini Board, two nine volt batteries, and a hand-held control unit which controls the speed with an attached potentiometer and direction with a touch key pad. In the design of this car, small size was one of the constraints. The Goal will be enhanced in the coming months to be able to enter the Micro-Robot World Cup Soccer Tournament held in Korea. This tournament was funded to promote the development of small, autonomous robots and intelligent systems that can cooperate with each other [16].

At North Carolina State University, a graduate level Mechatronics Design course has been introduced following the NSF sponsored workshop [17]. The objective of the course is to provide mechanical engineers with the background and training necessary to incorporate electronic components and microprocessors with software in the design of mechanical systems. The course consisted of a strong laboratory component following every lecture and two group projects. Having access to several video camera trackers after the NSF sponsored workshop, the instructor designed a mid-term project utilizing this smart product which was introduced during the workshop. The students were provided with the components of the tracker, and were asked to provide a guaranteed specification regarding performance. They were also required to study the phototransistor characteristics and use the results in their design. The 
final project consisted of modifying a Radio Shack car to perform intelligent navigation functions. Overall, the course was very well received by the students.

At GMI, an innovative (and expensive) approach is adopted in implementing the mechatronics course: GMI students are provided with a car, and asked to identify and disassemble mechatronic systems from this car [18]. These components are then reassembled and mounted on a bench for analysis. The students then model and simulate these systems using computers. Electronics of the system is analyzed, and the control algorithm is developed. These projects expose the students to mechanical, electronic, computer science using one system that synergistically integrates all these disciplines.

At West Virginia University, Mechatronics is introduced at IMSE 140, an introductory industrial engineering class [19]. After being introduced to C language and mechatronics concepts, the students work on several assignments which utilize the MiniBoard. Among these are: vary the tone of a beeper based on potentiometer settings, turn the stepper motor in desired direction, etc. These exercises were designed by faculty and senior students of $\mathrm{Cal}$ Poly, and were introduced to the participants during the early lab sessions of the NSF sponsored workshop. Similar exercises are utilized at Cal Poly's IME 101 (Introduction to Industrial and Manufacturing Engineering) class to introduce Mechatronics to undergraduates at the lower levels.

\section{Conclusions}

There are several programs supported by the National Science Foundation to develop Mechatronics curricula for undergraduate engineering education.

The NSF grant received by Cal Poly's IME Department provided the funds to prepare forty undergraduate faculty to develop Mechatronics courses nationwide as outlined in this paper. Other information on this ongoing project can be found at http://www.calpoly.edu/ salpteki.

The Synthesis Coalition -- a large scale project going into its seventh year is also sponsored by NSF. The members of this coalition have been developing innovative instructional delivery systems in Mechatronics. Some of the laboratory projects documented in this paper are among our deliverables as a member of this coalition. Other results of Synthesis supported work can be found at http://www.needs.org/.

An ongoing NSF sponsored project undertaken by San Jose State University's Mechanical Engineering Department focuses on the development of Mechatronics curriculum and laboratories. The results of this project can be found in this proceedings. Similar interdisciplinary projects are laying the foundation that will eventually lead to successful Mechatronics curricula.

\section{References}

1. Bradley, D.A., D. Dawson, N.C. Burd and A.J. Loader, "Mechatronics: Electronics in Products and Processes", Chapman Hall, 1991.

2. Carryer, E., "Smart Products", Presentation at Preparing the Leaders for Mechatronics Education Workshop, Cal Poly, June 1995.

3. Alptekin, S. E. and Jo Anne Freeman, "Mechatronics Education: Model and Implementation", Proceedings of Mechatronics'96, Cal Poly, 1996, pp: 1-9.

4. Kuwana, Shimoyama and Miura, "Steering Control of a Mobile Robot Using Insect Antennae", Workshop notes, Bio-Mechatronics, IEEE, 1996.

5. Alptekin, S.E., "Smart Products - A Tool for Mechatronics Education", Proceedings of International Conference on Recent Advances in Mechatronics - ICRAM'95, 14-16, Volume I, pp: 288-292, 1995.

6. Stedman, B., "Development of a Mechatronic Video Tracking System", Senior Project, Industrial and Manufacturing Engineering Department, Cal Poly, 1996.

7. Stedman, B., U. Menon, and S.E. Alptekin, "Video Tracker Application for Boeing, Proceedings of Mechatronics'96, Cal Poly, 1996, pp:135-150.

8. Ramasubramanian, M. K., Student Reports, North Carolina State University, MAE 589T Mechatronics Design Course, March 1996.

9. C. Elkan, Fuzzy Logic Lecture Notes, UC San Diego, Computer Science, March 1996.

10. Martin, F.G., "The Mini Board 2.0 Technical Reference", Media Laboratory, MIT, 1994.

11. Alptekin, S. E., (Editor), Proceedings of Mechatronics'96, Cal Poly, 1996.

12. Carryer, E., "Proceedings of the Workshop on Mechatronics Education", Stanford University, 1994. This document is also available on WWW at:

http://www.synthesis.org/Mechatronics-Workshop/

13. Koch, M., S. E. Alptekin, and N. Sweeney, "IME 356 Laboratory Manual", 1996, El Corral, Cal Poly.

14. Alptekin, S. E., "Mechatronics Design Studio: Sample Student Projects", Proceedings of Mechatronics96, S. Alptekin (Editor), Cal Poly, 1996, pp:180-185.

15. Gray, M., N. Stump and M. Garza, Project Report for IME 356 Manufacturing Automation, Cal Poly June 1996. 
16. KAIST, Micro-Robot World Cup Soccer Tournament, Taejon,

Korea (http://www.mirosot.org/)

17. Ramasubramanian, M. K., "Teaching Mechatronics Design at North Carolina State University", Proceedings of Mechatronics'96, S. Alptekin (Editor), pp: 108-115.

18. Mariappan, J., and J. Berry, "Mechatronics at GMI", Proceedings of Mechatronics'96, Cal Poly, pp: 78-83.
19. Gopalakrishnan, B., U.R. Shashikiran, and T.L. Sriram, "Educational and Research Approaches in Mechatronics", Proceedings of Mechatronics'96, Cal Poly, pp: 78-83. pp: 32-35.

This work is supported by the NSF grant \#9455124, Division of Undergraduate Education, Undergraduate Faculty Enhancement Program. 